\title{
Pheochromocytoma and Paraganglioma: From Clinical Findings to Diagnosis
}

\author{
(D) Nurcihan Aygun, (1) Mehmet Uludag \\ Department of General Surgery, University of Health Sciences Turkey, Sisli Hamidiye Etfal Teaching and Research Hospital, Istanbul, Turkey
}

\begin{abstract}
The majority of pheochromocytoma (PCC) and paraganglioma (PGL) are endocrine active tumors, and they cause clinical symptoms by secreting excess one or more catecholamines (epinephrine, norepinephrine, and dopamine) and their inactive metabolites (metanephrine, normetanephrine, 3-metoxythromine). Although signs and symptoms regarding excess catecholamine often develop in PCC and PGL (PPGL), non-functional PPGLs may present with local compression symptoms. Persistent, sometimes worsening hypertension is the most common finding and occurs in $80-90 \%$ of the patients. Classically defined symptom triad; headache, sweating and palpitations are seen in only $25 \%$ of the patients with PCC. The difference of clinical symptoms may be related to the tumor secretion, epinephrine or norepinephrine. All patients with signs and symptoms suggestive of catecholamine excess should be screened by biochemical tests regardless of whether they have hypertension or not. Not all patients with newly diagnosed hypertension need to be screened, but only patients with additional tips for catecholamine excess should be screened. Approximately $20 \%$ of the PPGLs are diagnosed in childhood, and the male/female ratio is $2 / 1.60-90 \%$ of pediatric patients present with hypertension. PPGL in pregnancy is rare, and the estimated incidence ranges between $1 / 15000-1 / 54000$. Although early diagnosis is the most important factor in preventing mortality, diagnosis is not as easy as it is a rare condition. Hypertension is a common complication in pregnancy, occurring in 5-10\%. Computed tomography should not be used as the imaging method during pregnancy; the first choice is magnetic resonance imaging with gadolinium or without contrast. Plasma free metanephrine or 24-hour urinary fractionated metanephrine level is recommended as a screening test for the diagnosis of PPGL in the Endocrine Society Clinical Practice Guideline. In suspicious situations, tests should be repeated. Since $40 \%$ of these patients have germline mutations, genetic tests are recommended for all patients with PPGL regardless of family history and age. Preoperative knowledge of germline mutations affects the surgical approach and the extent of adrenalectomy. After the biochemical diagnosis is made in PPGL, the tumor is localized with imaging methods to make the operation plan. In this review, we aimed to evaluate the clinical findings, diagnostic tests, and imaging studies for tumor localization in PPGL.
\end{abstract}

Keywords: Diagnosis; genetic testing; localization studies; pheocromocytoma and paraganglioma.

Please cite this article as "Aygun N, Uludag M. Pheochromocytoma and Paraganglioma: From Clinical Findings to Diagnosis. Med Bull Sisli Etfal Hosp 2020;54(3):271-280".

$\mathrm{P}$ heochromocytomas (PCC) originating from the adrenal chromaffin tissue of adrenal medulla and paragangliomas (PGL) originating from extra-adrenal chromaffin tissue are rare neuroendocrine tumors. The majority of PCC and
PGL are endocrine active tumors, and they may cause clinical symptoms by secreting excess one or more catecholamines (epinephrine, norepinephrine, and dopamine) and their inactive metabolites (metanephrine, normetaneph-

Address for correspondence: Nurcihan Aygun, MD. Sisli Hamidiye Etfal Tip Uygulama ve Arastirma Merkezi, Saglik Bilimleri Universitesi, Genel Cerrahi Anabilim Dali, Istanbul, Turkey

Phone: +90 5532779578 E-mail: nurcihanaygun@hotmail.com

Submitted Date: June 14, 2020 Accepted Date: June 26, 2020 Available Online Date: September 08, 2020

${ }^{\circ}$ Copyright 2020 by The Medical Bulletin of Sisli Etfal Hospital - Available online at www.sislietfaltip.org

OPEN ACCESS This is an open access article under the CC BY-NC license (http://creativecommons.org/licenses/by-nc/4.0/) 
rine, 3-metoxythromine). Some of them are not hormonally active. ${ }^{[1,4]}$ These tumors are abbreviated in the literature as PCC/PGL or PPGL; in this study, PPGL abbreviation will be used. ${ }^{[1,4]}$

In this review, we aimed to evaluate the clinical findings, diagnostic tests, and imaging studies for tumor localization in PPGL.

\section{Clinical Findings}

Although signs and symptoms related to excess catecholamine often develop in PPGL, non-functional PPGLs may present with local compression symptoms..$^{[5]}$

Persistent, sometimes worsening hypertension is the most common finding and occurs in $80-90 \%$ of patients. Half of the patients with hypertension have persistent hypertension, while the other half has paroxysmal hypertension. $5-15 \%$ of patients can be normotensive. ${ }^{[5]}$ Classically defined symptom triad, headache, sweating and palpitations are seen in only $25 \%$ of patients with PCC. ${ }^{[2]}$ Other symptoms may include pallor, nausea, vomiting, constipation, flushing, weight loss, weakness, fever, orthostatic hypotension, chest and/or abdominal pain, hyperglycemia, anxiety and psychiatric findings. Myocardial infarction, arrhythmia and stroke may occur depending on the degree of catecholamine excess. ${ }^{[2,6]}$

The difference of clinical symptoms may be related to tumor secretion, epinephrine or norepinephrine. Paroxysmal hypertension and palpitations, fainting, anxiety and hyperglycemia symptoms are more common in epinephrine-secreting PCCs. Norepinephrine-secreting PPGLs may cause more headaches, sweating and hypertension, and hypertension is more persistent, and paroxysmal condition is less. ${ }^{[2]}$ Acute (Takotsubo cardiomyopathy) or chronic (hypertrophic, dilated, obstructive) cardiomyopathy may occur with prolonged hypertension, chronic myocardial hypoxia and metabolic myocarditis due to hypercatecholaminemia. Limb ischemia, necrosis, gangrene and aortic dissection can be seen due to intense vasoconstriction. Renal function may be impaired due to vasoconstriction and even kidney failure may develop. Hypertensive retinopathy may develop in the eyes. ${ }^{[5]}$ Pheochromocytoma crisis may rarely occur. It is extremely important to differentiate this crisis from cardiogenic shock. There is multiple organ failure in this condition and the fever is above $40^{\circ} \mathrm{C}$, and additionally, there is encephalopathy, severe hypertension and/or hypotension. Treatment of this condition is the emergency resection of the tumor after the patient has been stabilized. ${ }^{[5]}$ Paroxysmal attacks can be provoked by tough exercise, sexual intercourse, defecation, alcohol intake, postural change and anesthesia. Pregnant patients may present with secondary preeclampsia or eclampsia due to the increase in hormone secretion with the pressure of the growing uterus on the tumor. Severe paroxysmal attacks may occur during an angiography, diagnostic biopsy, surgical intervention or delivery without diagnosis or patient preparation, and these attacks may even be fatal. ${ }^{[7]}$

\section{Which Patients should be Screened for Pheochromocytoma/Paraganglioma?}

All patients with signs and symptoms suggestive of catecholamine excess should be screened by biochemical tests regardless of whether they have hypertension or not. Not all patients with newly diagnosed hypertension need to be screened, but only patients with additional tips for catecholamine excess should be screened. Patients with blood pressure changes during conditions, such as anesthesia and surgical intervention, which are known to induce symptoms, should be screened biochemically. Apart from that, testing should be carried out in young, weak and hypertensive patients with newly diagnosed diabetes. Patients with adrenal incidentaloma should be screened for pheochromocytoma, although they have no symptoms. In addition, patients with hereditary syndromes or hereditary predisposition who may have PPGL should also be screened biochemically (Fig. 1). ${ }^{[6,8]}$

\section{Pheochromocytoma/Paraganglioma in Children}

Approximately $20 \%$ of PPGLs are diagnosed in childhood, and the male/female ratio is $2 / 1$. The mean age of presentation in children is $11-13$. The cause of $0.5-2 \%$ of hypertension seen in children is PPGL. $60-90 \%$ of pediatric patients present with hypertension. ${ }^{[9,10]} 80 \%$ of PPGLs in children are hereditary, and the frequency of mutations in children is as follows: $49 \% \mathrm{VHL}$ mutation, $15 \%$ SDHB mutation, $10 \%$ SDHD mutation, 4\% NF1 mutation. ${ }^{[44]}$ In children, a second primary paraganglia develops over time, reaching $50 \%$ in 30 years after this initial diagnosis. ${ }^{[4]}$ As hereditary disease rate is high, genetic tests should be performed in all patients. All patients with genetic mutations should be followed throughout their lifetime due to the recurrence and metastatic disease. ${ }^{[10]}$

\section{Pheochromocytoma/Paraganglioma in Pregnancy}

PPGL in pregnancy is rare and the estimated incidence ranges between 1/15000-1/54000. ${ }^{[1]}$ Mortality risk for both mother and baby is approximately $50 \%$ when PPGL is not diagnosed during pregnancy. If the prenatal diagnosis is made and appropriate treatment is performed, maternal 


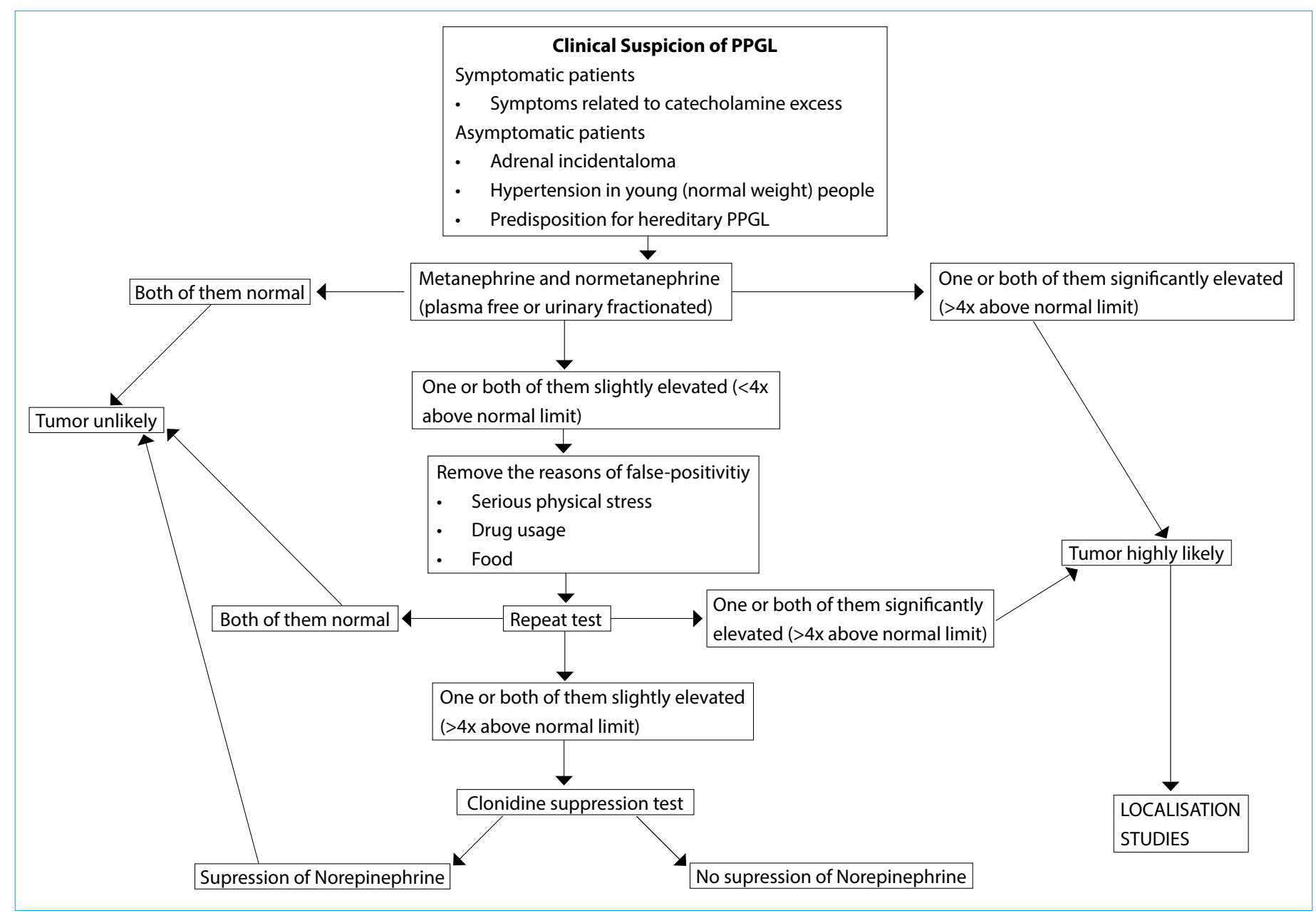

Figure 1. Biochemical testing algorithm in terms of clinical suspicion of PPGL.

mortality decreases to $5 \%$ and fetal mortality to $15 \% .{ }^{[12]}$ In a review in which 77 births after the year 2000 were evaluated, it was reported that when the diagnosis was made prenatally, the survival was $100 \%$ for the mother and $88 \%$ for the fetus, and when the prenatal diagnosis could not be established, the mortality rate was reported to be $29 \%$ for both the mother and the fetus. ${ }^{[13]}$ In addition, maternal and fetal mortality rates in PGLs are lower than PCC; $3.6 \%$ vs. $9.8 \%$ and $12 \%$ vs. $16 \%$, respectively. Although the mortality rate is lower in PGL, both maternal and fetal mortality are still higher than the general obstetric population. ${ }^{[14]}$ Death is due to hypertensive crisis leading to the acute coronary syndrome, cardiomyopathy, arrhythmias, stroke and shock. Although early diagnosis is the most important factor in preventing mortality, diagnosis is not easy as it is a rare condition. ${ }^{[11]}$ Hypertension is a common complication in pregnancy, occurring in 5-10\%. ${ }^{[15]}$ It can be difficult to differentiate PPGL-induced hypertension due to common causes of hypertension, such as pre-existing chronic hypertension, pregnancy-related gestational hypertension and preeclampsia. ${ }^{[12]}$ Its clinical presentation in pregnancy is not different from other patients. Approximately $90 \%$ of patients report one or more prenatal symptoms during pregnancy. However, $70 \%$ of patients can be diagnosed before birth, and $30 \%$ can be diagnosed after birth or postmortem..$^{[11]}$

Symptoms and signs can be progressive as the pregnancy progresses. This can be explained by the stimulation of the tumor by growing uterus, uterine contractions, fetus movements and abdominal palpation. ${ }^{[11,16]}$ In addition, estrogen is claimed to be a growth factor for adrenal tumors. ${ }^{[16]}$ These factors may sometimes induce a PPGL hypertensive crisis that includes life-threatening problems, such as acute coronary syndrome, cardiomyopathy, arrhythmias, stroke, syncope and shock. More rarely non-cardiac pulmonary edema, aortic dissection, or unexplained peripartum cardiomyopathy can be seen. It should be kept in mind that when a pregnant woman presents with one of these serious acute cardiovascular emergencies, even if she does not have known hypertension, PPGL may also exist among etiologies. The highest risk for these dangerous emergencies is associated with the peripartum period. ${ }^{[11]}$ 
Catecholamines play a central role in compliance and protection against stressful stimuli during pregnancy and birth. Plasma and urine catecholamine levels do not continuously increase in healthy pregnant women. ${ }^{[17]}$ Maternal plasma catecholamine levels increase slightly even in preeclampsia. ${ }^{[18]}$ Maternal catecholamines cannot pass through the placental barriers and umbilical cord blood contains less than $10 \%$ of maternal catecholamine concentrations even in patients with PPGL. Placenta plays a key role in the protection of the fetus from tumor-induced high catecholamine levels. This is due to the presence of norepinephrine carriers and catecholamine metabolizing enzymes (such as MAO and COMT) in the placenta. These carriers facilitate norepinephrine uptake, while enzymes inactivate catecholamines. ${ }^{[19]}$ Although the fetus itself has a high secretion rate of catecholamines, an extremely effective clearance results in low catecholamine levels in the circulation. ${ }^{[20]}$ Catecholamine levels are particularly high during birth. This helps the fetus adapt to its stressful journey in the birth canal and early postnatal life. ${ }^{[21]}$

Patients with PPGL may have sustained hypertension, paroxysmal hypertension, or paroxysmal hypertensive attacks over persistent hypertension. Sustained hypertension during pregnancy is associated with intrauterine growth retardation and accompanying adverse effects, such as preeclampsia and perinatal death. Catecholamine levels in the mother's blood may rise excessively, which may jeopardize the function of the placenta and many organs. Temporary sudden catecholamine increases in the mother's circulation can cause serious harmful effects in uteroplacental circulation. The major effect of this situation is the strong intermittent vasoconstriction in this specific and vulnerable vascular bed. This results in placental detachment and increased fetal mortality due to intrauterine hypoxia. ${ }^{[11]}$ Catecholamine levels do not change in a healthy pregnancy except for the period from the onset of labor until the second post-partum day. Urinary catecholamines increase 1.7-6.6 times in preeclamptic patients admitted to the hospital; however, plasma catecholamines tend to be decreased or normal. ${ }^{[22]}$ Biochemical tests for diagnosis are not different from other patients when there is a clinical suspicion during pregnancy. Urine or plasma free catecholamine metabolites are used for diagnosis or to exclude the diagnosis. ${ }^{[11]} \mathrm{CT}$ should not be used as the imaging method during pregnancy; the first choice is MRI with or without gadolinium contrast. ${ }^{[4,7]}$ Functional imaging methods are contraindicated during pregnancy. ${ }^{[7,23]}$ Surgical intervention to the tumor during pregnancy is recommended before 24 weeks or after birth. ${ }^{[1]}$ The choice of delivery in patients with PPGL depends on various factors, such as the number of births, previous cesarean delivery, the success of medical treatment, and personal preference of the patient. In most cases, cesarean delivery is still preferred as a way of safe delivery. Epidural, general or combined anesthetic techniques are successfully used for cesarean delivery. ${ }^{[11,23]}$

\section{Diagnosis of Pheochromocytoma and Paraganglioma}

\section{Biochemical Tests}

When PPGL is suspected, biochemical tests should be applied to diagnose or exclude the disease. Since plasma levels of catecholamines can be affected by many physiological and pathological conditions, and the half-life of catecholamines is very short, the suitability of serum catecholamines for diagnosis is low. ${ }^{[24]}$ In case of suspicion of PPGL, diagnosis is made by 24-hour urine measurements of catecholamines or metabolites and serum metanephrine measurements. Although fractionated urinary catecholamines are very sensitive for PCC diagnosis, their specificity is low. ${ }^{[24]}$

24-hour urine VMA is not recommended due to its false negativity rates. ${ }^{[1]}$ Plasma free metanephrine or 24-hour urinary fractionated metanephrine level is recommended as a screening test for the diagnosis of PPGL in the Endocrine Society Clinical Practice Guideline. ${ }^{[4]}$ Although metanephrine measurement is reported to be appropriate in spot urine samples, there is no evidence to suggest this to replace 24-hour urine collection. Improper urine collection may cause false low results in children or elderly patients.

Blood samples should be taken in the supine position and after resting the patient in the supine position for at least 30 minutes to avoid false positivity. ${ }^{[4]}$ When the test is taken while standing, the false positivity rate increases 2.8 times compared to the supine position. ${ }^{[25]}$ It should not be forgotten that the serum measurement is more convenient and that the compliance is better compared to 24-hour urine collection. ${ }^{[4]}$ When urine testing is carried out, urine creatinine measurement should be done to confirm proper urine collection. ${ }^{[4,26]}$

The Endocrine Society recommends both serum or urine metanephrine measurements in its practice guideline, with no suggestions for the superiority of one over the other. ${ }^{[4]}$ In a recent study, it was revealed that despite the low false negativity rate of both plasma and urine free metanephrine measurements in PPGL diagnosis, it had been demonstrated that the diagnostic performance of plasma measurements is higher. ${ }^{[27]}$

Dopamine- $\beta$-hydroxylase deficiency may also be present in PPGL, especially in SDHx mutation carriers. In this case, there is a problem in converting dopamine to norepineph- 
rine, and its metabolite 3-methoxytyramine (3MT) accumulates. ${ }^{[28]}$ In this case, plasma 3-MT measurement can be used for evaluation for diagnosis. ${ }^{[27]}$

Some rare mutation carriers have tyrosine hydroxylase deficiency, which is the limiting enzyme in catecholamine synthesis; these cases can be described as weak or nonfunctional. ${ }^{[28]}$ In such cases, chromogranin A in the granules in chromaffin cells can be used as a diagnostic marker as a complement to metanephrine ${ }^{[29]}$ Many well-differentiated neuroendocrine tumors secrete chromogranin A. Many diseases and treatments can cause an increase in chromogranin A level, which would result in false positivity. Especially if the patient is using a proton-pump inhibitor (PPI), it should be stopped optimally two weeks before measurement. ${ }^{[28]}$

Depending on the mutation, both metanephrine or normetanephrine, or only metanephrine may increase in patients with chromaffin cell tumors. In very rare cases, normetanephrine may increase alone or in combination with 3-MT. ${ }^{[28]}$

Provocative tests have been used for the diagnosis of PCC in the past; today, biochemical tests have replaced them and these tests are not used. However, clonidine suppression test can be used to differentiate the increased secretion of norepinephrine due to sympathetic activation, which is rare and catecholamine secretion by the autonomic nervous system tumor. Clonidine suppresses catecholamine synthesis by blocking the presynaptic a 2 receptor. It is based on the suppression of catecholamine secretion in the blood taken three hours after oral $0.3 \mathrm{mg}$ clonidine administration after taking the blood sample from the patient in a supine position. If it is suppressed, it favors sympathetic activity, and if not, it favors the autonomous catecholamine-secreting tumor. ${ }^{[30]}$

Some diseases, drugs and foods cause an increase in catecholamines and metabolites, causing false positivity. Serious physical stresses, such as obstructive sleep apnea, recent surgical intervention, stroke and myocardial infarction, may cause a false increase in metanephrine. Conversely, methyl glutamine and iodine-containing contrast agents. may cause false lower metanephrine levels for 72 hours after applying. ${ }^{[7]}$ The use of tricyclic antidepressants, phenoxybenzamine, a-blockers, cocaine, levodopa, MAO inhibitors, sympathomimetics (ephedrine, albuterol, amphetamine), sulfasalazine may cause increased catecholamine metabolites and cause false-positive results. ${ }^{[1,2,4]}$ Caffeine, black tea, alcohol, banana, cheese, almond, hazelnut, chocolate, egg and vanilla should be discontinued three days before the urine or serum metanephrine test. ${ }^{[28]} \mathrm{Com}-$ bined increase in two or more metabolites suggests a high probability of PPGL. ${ }^{[28]}$

In patients undergoing PPGL screening, normal serum or urine catecholamine metabolites/catecholamine measurements may exclude the disease with high sensitivity. More than a 4-fold increase in catecholamine metabolites is most likely associated with the diagnosis of PPGL and research should be conducted by imaging methods. Tests should be repeated in cases of slight increases, such as 1-4 times the upper limit of the normal value. The above factors, which may cause false positivity, should be reassessed, and tests should be repeated after these factors are eliminated. The possibility of a tumor can be excluded if the tests are normal and if the patient does not have a high-risk clinical condition, such as a hereditary disease. Again, if an increase of 1-4 times, the upper limit of normal is detected, the clonidine suppression test can be performed in these patients. If there is a suppression of norepinephrine in the clonidine test, the tumor may most likely be excluded. If there is no suppression, the tumor should be investigated by imaging methods (Fig. 1). ${ }^{[6,8]}$ It is recommended to perform both serum and urine tests together in the repeat test. ${ }^{[2]}$ Preoperative chromogranin A evaluation is recommended for patients with normal plasma or urinary metanephrine and normetanephrine and 3MT levels before surgery. ${ }^{[31]}$

In summary, plasma free metanephrine and normetanephrine measurement, or 24-hour urine metanephrine and normetanephrine measurement, should be performed in PPGL screening and follow-up. In suspicious situations, tests should be repeated (Fig. 1). Particularly in cases with PGL suspicion, metastatic disease or in SDHx mutation carriers, additional 3-MT measurement is used. Chromogranin A should be measured in patients with suspected PPGL or with non-functional PPGL diagnosis. ${ }^{[27]}$

\section{Genetic Testing}

Knowing which a patient has specific genetic basics can guide biochemical tests, specific imaging methods, and appropriate personal treatments. ${ }^{[28]}$ In the past, genetic testing was recommended for those diagnosed at a young age, or with a family history or have a multifocal disease. However, since $40 \%$ of these patients have germline mutations, genetic tests are recommended for all patients with PPGL regardless of family history and age. ${ }^{[4,31,32]}$ Preoperative knowledge of germline mutations affects the surgical approach and the extent of adrenalectomy. ${ }^{[33]}$ Different somatic mutations are associated with different risks of metastases, and somatic mutations, like germline mutations, may also affect prognosis. Somatic mutations may also contribute to targeted chemotherapy selection. Therefore, the analysis of somatic mutations in the extracted tumor 
material can provide additional information regarding the follow-up and treatment of the patient. ${ }^{[28]}$

\section{Localization Studies}

After the biochemical diagnosis is made in PPGL, the tumor is recommended to be localized with imaging methods to make the operation plan. ${ }^{[4]}$ Localization studies can be examined under two headlines as anatomical localization studies and functional localization studies.

\section{Anatomical Imaging Studies}

Anatomical imaging methods are computed tomography (CT) and magnetic resonance imaging (MRI). Ultrasound is not generally recommended due to its suboptimal sensitivity. ${ }^{[4]}$

\section{Computed Tomography}

When the adrenal protocol is applied in CT for PCC, it is below 10 Hounsfield units ( $\mathrm{HU}$ ) in lipid-rich adenomas and above $10 \mathrm{HU}$ in PCC in non-contrasted sections. In the adrenal protocol, a significant increase in contrast enhancement in the arterial phase and delayed venous phase washout (less than absolute $60 \%$ or relative $40 \%$ washout in the late phase in the images taken after 7-15 minutes) are detected and they can be differentiated from adrenal adenoma. ${ }^{[34]}$

In a meta analysis of ten studies, $35 \%$ of PCC showed the washout properties of adrenal adenoma, and the mean sensitivity for adrenal washout was detected as $97 \%$, while the specificity was $67 \%$. In the diagnosis of PCC, other findings should be used besides the washout rate. ${ }^{[35]}$ Nonionic contrast agents can be used safely in patients without adrenergic receptor blockade in contrast $\mathrm{CT}^{[4]}$ Modern contrast CTs today can detect lesions over $5 \mathrm{~mm}$ in size. ${ }^{[36]}$ Contrast enhancement may vary depending on tumor di- ameter, intratumoral bleeding or necrosis. CT characteristics of PGLs are similar to PCC. ${ }^{[2]}$ Although excellent results (88-100\%) are reported with contrast CT in the localization of PPGL, ${ }^{[4]}$ sensitivity decreases to $65 \%$, especially in bilateral PCC and PGLs. ${ }^{[36]}$ Since $C T$ has excellent resolution in abdomen, ,pelvis and thorax, it is the first choice for anatomical imaging. ${ }^{[4]}$

\section{Magnetic Resonance Imaging}

On MRI; PCCs, like most tumors, show hypointense signal on T1-weighted images and hyperintense signal on T2weighted images. Despite the high sensitivity of MRI for this appearance, its specificity is low. ${ }^{[37]}$ Classically, $30 \%$ of pheochromocytomas show a "light bulb sign" in the T2weighted images, which is a very hyperintense signal. ${ }^{[36]}$ Especially in PGLs, there is a "salt-and-pepper" appearance consisting of hypointense areas with low signal intensity corresponding to tumor vascularity and hyperintense areas seen in hemorrhagic areas of the tumor. This sign is mostly described in the head and neck region PGLs. However, this view is not specific for PGLs as it can be seen in other vascular tumors. ${ }^{[3]}$ Signal heterogeneity due to bleeding, cystic degeneration and calcifications in the tumor are helpful features in differentiating PCCs from benign adenomas. Signal characteristics of PGLs are similar to $P C C$ in $M R I$, as in $C T .{ }^{[37]} \mathrm{MRI}$ has the same sensitivity as $\mathrm{CT}$ in adrenal PCC and its sensitivity is close to $100 \%$ in familial PCC and PGL. ${ }^{[6]}$

$M R I$ is recommended in patients with metastatic PPGLs, for detection of head and neck PGLs, in patients with surgical clips that may cause artifacts in $\mathrm{CT}$, in children, pregnant patients, patients with germline mutation and in patients who have been exposed to excessive radiation recently who are at risk for radiation. In patients with an intracranial

Table 1. Recommended nuclear imaging algorithm for cases of pheochromocytomas and paragangliomas by European Association of Nuclear Medicine ${ }^{38}$

\begin{tabular}{|c|c|c|c|}
\hline & First Choice & Second Choice & $\begin{array}{l}\text { Third Choice (if }{ }^{18} \mathrm{~F}-F D O P A \\
{ }^{68} \mathrm{Ga} \text {-DOTA-SSA is not available) }\end{array}$ \\
\hline Sporadic PCC & ${ }^{18} \mathrm{~F}-\mathrm{FDOPA}$ or $123 \mathrm{I}-\mathrm{MIBG}$ & ${ }^{68} \mathrm{Ga}-\mathrm{DOTA}-\mathrm{SSA}$ & ${ }^{18} \mathrm{~F}-\mathrm{FDG}$ \\
\hline Inherited PCC/PCL (include: & ${ }^{18} \mathrm{~F}-\mathrm{FDOPA}$ & ${ }^{123}$ I-MIBG or 68Ga-DOTA-SSA & ${ }^{18} \mathrm{~F}-\mathrm{FDG}$ \\
\hline \multicolumn{4}{|c|}{ NF1/RET/VHL/MAX, except:SDHx } \\
\hline Sporadic HNPCL & ${ }^{68} \mathrm{Ga}-\mathrm{DOTA}-\mathrm{SSA}$ & ${ }^{18} \mathrm{~F}-\mathrm{FDOPA}$ & \\
\hline \multicolumn{4}{|c|}{ Extra-adrenal sympathetic and/or } \\
\hline multifocal and/or metastatic & ${ }^{68} \mathrm{Ga}-\mathrm{DOTA}-\mathrm{SSA}$ & ${ }^{18} \mathrm{~F}-\mathrm{FDG}$ and $18 \mathrm{~F}-\mathrm{FDOPA}$ & ${ }^{18} \mathrm{~F}-\mathrm{FDG}$ and ${ }^{123} \mathrm{I}-\mathrm{MIBG}$ \\
\hline PGL and/or SDHx mutation & & & \\
\hline
\end{tabular}

PCC: phaeochromocytoma; [123 I]MIBG: iodine-123-labelled meta-iodobenzylguanidine; ${ }^{18} \mathrm{~F}-\mathrm{FDA}$ : fluorine-18-labelled fluorodopamine; ${ }^{18} \mathrm{~F}-\mathrm{FDOPA}$ : fluorine18-labelled fluorodihydroxyphenylalanine; ${ }^{18} \mathrm{~F}$-FDG: fluorine-18-labelled fluorodeoxyglucose; ${ }^{68} \mathrm{Ga}$-DOTA-SSA: gallium-68-labelled- tetraazacyclododecanet etraacetic acid- somatostatin analogue; NF1/RET/VHL/MAX: neurofibromin 1/rearranged during transfection proto-oncogene/von Hippel-Lindau/mycassociated factor X,HNPGL: head and neck paraganglioma; SDHx: succinate dehydrogenase subunits. 
aneurysm clip, MRI should not be performed as the clip may prevent the detection of small lesions at the skull base. ${ }^{[4]}$

\section{Functional Localization Studies}

Anatomical imaging methods are generally sufficient for surgical planning in adrenal-derived PCCs. However, the decision for whether the patient needs additional whole body anatomical imaging or functional imaging is made according to the the diameter of the tumor, its biochemical profile, the probability of metastasis and the possibility of the tumor being hereditary. Whole-body CT or MRI or functional radionuclide imaging is recommended to evaluate the possibility of metastatic or multiple focus, which may affect the surgical extension in all patients with PPGL, except for patients who are diagnosed as PCC less than $5 \mathrm{~cm}$ in size, secreting epinephrine at presentation, which has a low risk of metastasis. ${ }^{[28]}$ The sensitivity and specificity of functional imaging depend on catecholamine metabolism and secretion, glucose metabolism, tumor somatostatin receptor status and radiopharmaceutical to be used accordingly. ${ }^{[2]}$

In functional imaging, if possible, hybrid SPECT/CT or PET/ CT imaging methods are recommended, in which functional and anatomical imaging are integrated. ${ }^{[38]}$ Here, the four most frequently used nuclear imaging recently will be given. The nuclear medicine imaging recommendations of the European Association of Nuclear Medicine to be preferred in different clinical situations in PPGL are given in Table 1.

\section{${ }^{123}$ I-metaiodobenzylguanidine (123I-MIBG) Scintigraphy}

In this method, the scintigraphic localization of the tumor is based on the accumulation of MIBG, a norepinephrine analogue, in catecholamine producing tumors. ${ }^{123}$ |-MIBG scintigraphy is recommended in cases where PCC cannot be evaluated clearly in CT or MRI. Although sensitivity in PCC is reported as $83-100 \%$ and specificity as $95-100 \%$ in small studies, in larger studies, the sensitivity decreases to $52-75 \%$ in extraadrenal, multiple, recurrent, hereditary PGLs. The sensitivity of PGLs in the head and neck region and those with SDHB mutation drops below $50 \% \cdot{ }^{[38]}$ Since ${ }^{123}$ I-MIBG scintigraphy provides lower radiation and higher image quality, it is preferred over ${ }^{131}$ I-MIBG scintigraphy. ${ }^{[1]}$ For ${ }^{123} \mathrm{I}-\mathrm{MIBG}$ scintigraphy, thyroid should be blocked by administration of $130 \mathrm{mg} / \mathrm{kg}$ ( $30 \mathrm{~min}$ to $2 \mathrm{~h}$ ) potassium iodide to the patient one hour before the injection of the substance. ${ }^{[39]}$

However, ${ }^{123}$ I-MIBG scintigraphy is a widely used method for patient selection for ${ }^{131}$ I-MIBG treatment. ${ }^{[38,39]}$

\section{PET/CT with ${ }^{68}$ Gallium-Labeled Somatostatin Analogues $\left({ }^{68} \mathrm{Ga}-\mathrm{DOTA}\right.$-SSA PET/CT)}

PPGLs most often express type 2 of 5 types of somatostatin receptors. Some PGLs express the type 1 receptor. ${ }^{[38]}$ Three different somatostatin analogues bound to ${ }^{68} \mathrm{Gal}-$ lium $\left({ }^{68} \mathrm{Ga}\right)$ - DOTA (tetraaza cyclododecane tetraacetic acid) are used to display somatostatin receptors: DOTATATE (DOTA(0)-Tyr(3)-octreotate), DOTATOC (DOTA(0)- Phe(1)Tyr(3)-octreotide), DOTANOC (DOTA(1)- Nal(3)-octreotide). ${ }^{[38]}$ DOTATATE has a greater affinity for type 2 somatostatin receptors than others. The rate of detection of PPGL was higher than other methods with ${ }^{68} \mathrm{Ga}$-DOTA-SSA PET/CT in the last meta-analysis; $93 \%$ with ${ }^{68} \mathrm{Ga}$-DOTA-SST PET, $80 \%$ with ${ }^{18} \mathrm{~F}-\mathrm{FDOPA}$ PET/CT, $74 \%$ with ${ }^{18} \mathrm{~F}-\mathrm{FDG}$ PET/CT and $38 \%$ with ${ }^{123 / 131}$ I-MIBG scintigraphy. ${ }^{[40]}$ Patient- and lesion-based lesion detection rate in extra-adrenal PGLs was $98 \%$ and $95 \%$ with ${ }^{68} \mathrm{Ga}-\mathrm{DOTA}-\mathrm{SSA} \mathrm{PET} / \mathrm{CT}$, and was $99 \%$ and ${ }^{68} \%$ with ${ }^{18} \mathrm{~F}-\mathrm{FDOPA} \mathrm{PET} / \mathrm{CT}$, respectively. ${ }^{[38]}$

${ }^{68} \mathrm{Ga}$-DOTA-SSA PET/CT can detect SDH related lesions more than ${ }^{18} \mathrm{~F}-\mathrm{FDG} \mathrm{PET} / \mathrm{CT} \cdot{ }^{[41]}$ The most sensitive method for detecting, especially the head and neck PGLs, is ${ }^{68} \mathrm{Ga}$ DOTA-SSA PET/CT. ${ }^{[38]}$

\section{${ }^{18}$ F-FDOPA PET/CT}

This method is used with ${ }^{18} \mathrm{~F}$-labeled DOPA (fluoro dihydroxyphenylalanine). Since DOPA is the precursor to all endogenous catecholamines, ${ }^{18} \mathrm{~F}-\mathrm{FDOPA}$ is quickly taken up by PPGL tumor cells. Compared to other radiopharmaceuticals, uptake of ${ }^{18} \mathrm{~F}$-FDOPA by normal adrenal tissue is more limited. ${ }^{18} \mathrm{~F}$-FDOPA is very helpful in detecting small PCCs. ${ }^{[42]}$

Sensitivity in detecting metastatic disease is 93\% in SDHB negative patients and $20 \%$ in SDHB positive patients. In recent studies, it has been observed that VHL, EPAS1 (HIF2A) and $\mathrm{FH}$ have very high sensitivity in detecting PPGLs with multiple, recurrent and high metastatic potentials. ${ }^{[38]}$

\section{${ }^{18}$ F-FDG PET/CT}

${ }^{18}$ Flor-labeled FDG (Fluorodeoxyglucose) is taken by glucose membrane transporters on the tumor cells and is generally preferred for the imaging of metastatic tumors. ${ }^{[38,43]}$

Today, it is mostly preferred for the evaluation of patients with extra-adrenal PPGL with SDH mutation, multifocality or metastasis. ${ }^{[43]}$

\section{Which Imaging Method to Whom?}

Abdominal contrast $\mathrm{CT}$, including the entire retroperitoneal area in patients with biochemically increased metanephrine or catecholamine levels, presenting with clinical symp- 
toms and findings, should be performed, or MRI in patients, where $\mathrm{CT}$ is not suitable. If this region is negative for the tumor, thorax, pelvis and head and neck should be scanned with MRI. ${ }^{[44]} \mathrm{CT}$ and MRI can be combined in head and neck PGLs. 3D contrast-enhanced MR angiography increases the rate of detection of PGL in this region and contributes to the differentiation of schwannoma, plasmacytoma, meningioma and vascular malformation. In CT, jugular foramen and hypotympanum can be evaluated better in the temporal bone region. ${ }^{[2]}$

If the incidentally detected mass in the adrenal or retroperitoneal region is $>10 \mathrm{HU}$ in $\mathrm{CT}$, biochemical tests should be performed. If metanephrine or catecholamines are significantly increased, contrast CT or MRI should be performed. ${ }^{[28]}$ Whole-body CT or MRI or functional radionuclide imaging is recommended for preoperative metastasis evaluation in all patients with PPGL except patients with PCC below $5 \mathrm{~cm}$ diameter in size, secreting epinephrine, with a low probability of metastasis. Preoperative troakoabdomial CT or MRI can reveal metastases, such as peritumoral lymph node metastasis, and these can be confirmed in surgery. Functional imaging methods can reveal distant metastases that cannot be seen by anatomical imaging methods or intraoperative exploration. The rate of metastatic disease is higher in some cases. The risk of malignancy is higher in extra-adrenal PGLs than in adrenal PCCs. Patients with high 3MT levels have a high risk of malignancy. Primary metastatic tumor or recurrence is common in patients with SDHB mutation. $\mathrm{FH}$ and $\mathrm{MDH} 2$ mutations also have a high risk of metastatic disease. The European Endocrinology Society recommends functional imaging in addition to $C T$ or MRI in high-risk patients in these categories. ${ }^{[3]}$ In addition, functional imaging methods can be used to confirm whether norepinephrine-secreting adrenal or extra-adrenal tumors are true PPGLs.

As a functional imaging method, in sporadic $P C C$, the first choice should be ${ }^{18} \mathrm{~F}-\mathrm{FDOPA}$ PET/CT or ${ }^{123}$ /-MIBG scintigraphy and the second choice should be ${ }^{68} \mathrm{Ga}$-DOTA-SSA PET/ CT. In hereditary NF1/RET/VHL/MAX mutations, the first choice should be ${ }^{18} \mathrm{~F}-\mathrm{FDOPA}$ PET/CT scintigraphy, the second choice should be ${ }^{123}$-MIBG or ${ }^{68} \mathrm{Ga}-\mathrm{DOTA}-\mathrm{SSA}$ PET/CT. In extra-adrenal sympathetic and/or multifocal and/or metastatic PGL and/or SDHx mutations, the first choice should be ${ }^{68} \mathrm{Ga}-\mathrm{DOTA}-\mathrm{SSA} P \mathrm{PET} / \mathrm{CT}$, the second choice should be ${ }^{18} \mathrm{~F}-\mathrm{FDG} \mathrm{PET} / \mathrm{CT}$ and/or ${ }^{18} \mathrm{~F}-\mathrm{FDOPA}$ PET/CT. In sporadic head and neck PGLs, the first choice should be ${ }^{68} \mathrm{Ga}$-DOTA-SSA $\mathrm{PET} / \mathrm{CT}$ and the second should be ${ }^{18} \mathrm{~F}-\mathrm{FDOPA} \mathrm{PET} / \mathrm{CT}$. If these methods are not applicable, in general, ${ }^{18}$ F-FDG PET/ CT can be applied as the third choice for all conditions. ${ }^{[38]}$ (Table 2).

\section{Biopsy}

Biopsy is not recommended in PPGLs. Biopsy can be performed if there is an extra-adrenal tumor in the patient's history, if the tumor is nonfunctional, if the decision cannot be made with imaging whether it is benign or not and if biopsy will change the treatment of the patient. Biopsy can be considered in selected patients with potentially nonfunctional PPGL with negative biochemical tests. ${ }^{[28]}$ If a biopsy is performed in a suspicious lesion in the adrenal or retroperitoneal region, a biochemical work-up for the hormonal activity must be performed before the biopsy. ${ }^{[28]}$

\section{Disclosures}

Peer-review: Externally peer-reviewed.

Conflict of Interest: None declared.

Authorship Contributions: Concept - N.A., M.U.; Design - N.A., M.U.; Supervision - M.U.; Materials - N.A., M.U.; Data collection \&/ or processing - N.A.; Analysis and/or interpretation - M.U.; Literature search - N.A.; Writing - N.A., M.U.; Critical review - M.U.

\section{References}

1. Tevosian SG, Ghayee HK. Pheochromocytomas and Paragangliomas. Endocrinol Metab Clin North Am 2019;48:727-50. [CrossRef]

2. Patel D, Phay JE, Yen TWF, Dickson PV, Wang TS, Garcia R, et al. Update on Pheochromocytoma and Paraganglioma from the SSO Endocrine/Head and Neck Disease-Site Work Group. Part 1 of 2: Advances in Pathogenesis and Diagnosis of Pheochromocytoma and Paraganglioma. Ann Surg Oncol 2020;27:1329-37. [CrossRef]

3. Aygun N, Uludag M. Pheochromocytoma and Paraganglioma: From Epidemiology to Clinical Findings. Sisli Etfal Hastan Tip Bul 2020;54:159-68. [CrossRef]

4. Lenders JW, Duh QY, Eisenhofer G, Gimenez-Roqueplo AP, Grebe $\mathrm{SK}$, Murad MH, et al; Endocrine Society. Pheochromocytoma and paraganglioma: an endocrine society clinical practice guideline. J Clin Endocrinol Metab 2014;99:1915-42. [CrossRef]

5. Zuber SM, Kantorovich V, Pacak K. Hypertension in pheochromocytoma: characteristics and treatment. Endocrinol Metab Clin North Am 2011;40:295-311. [CrossRef]

6. Kiernan CM, Solórzano CC. Pheochromocytoma and Paraganglioma: Diagnosis, Genetics, and Treatment. Surg Oncol Clin N Am 2016;25:119-38. [CrossRef]

7. Frunzac RW, Grant CS. Pheochromocytoma. In: Clark OH, Duh QY, Kebebew E, Gosnell JE, Shen WT, editors. Textbook of Endocrine Surgery. 3rd ed. Jaypee Brothers Medical Publishers; 2016. p. 1047-67. [CrossRef]

8. van Berkel A, Lenders JW, Timmers HJ. Diagnosis of endocrine disease: Biochemical diagnosis of phaeochromocytoma and paraganglioma. Eur J Endocrinol 2014;170:R109-19. [CrossRef]

9. Bholah R, Bunchman TE. Review of Pediatric Pheochromocytoma and Paraganglioma. Front Pediatr 2017;5:155. [CrossRef] 
10. Bausch B, Wellner U, Bausch D, Schiavi F, Barontini M, Sanso G, et al. Long-term prognosis of patients with pediatric pheochromocytoma. Endocr Relat Cancer 2013;21:17-25. [CrossRef]

11. Lenders JWM, Langton K, Langenhuijsen JF, Eisenhofer G. Pheochromocytoma and Pregnancy. Endocrinol Metab Clin North Am 2019;48:605-17. [CrossRef]

12. Lenders JW. Pheochromocytoma and pregnancy: a deceptive connection. Eur J Endocrinol 2012;166:143-50. [CrossRef]

13. Biggar MA, Lennard TW. Systematic review of phaeochromocytoma in pregnancy. Br J Surg 2013;100:182-90. [CrossRef]

14. Wing LA, Conaglen JV, Meyer-Rochow GY, Elston MS. Paraganglioma in Pregnancy: A Case Series and Review of the Literature. J Clin Endocrinol Metab 2015;100:3202-9. [CrossRef]

15. Vest AR, Cho LS. Hypertension in pregnancy. Curr Atheroscler Rep 2014;16:395. [CrossRef]

16. van der Weerd K, van Noord C, Loeve M, Knapen MFCM, Visser W, de Herder WW, et al. Endocrinology in pregnancy: Pheochromocytoma in pregnancy: case series and review of literature. Eur J Endocrinol 2017;177:R49-58. [CrossRef]

17. Natrajan PG, McGarrigle HH, Lawrence DM, Lachelin GC. Plasma noradrenaline and adrenaline levels in normal pregnancy and in pregnancy-induced hypertension. Br J Obstet Gynaecol 1982;89:1041-5. [CrossRef]

18. Oian P, Kjeldsen SE, Eide I, Maltau JM. Increased arterial catecholamines in pre-eclampsia. Acta Obstet Gynecol Scand 1986;65:613-7. [CrossRef]

19. Nguyen TT, Tseng YT, McGonnigal B, Stabila JP, Worrell LA, Saha S, et al. Placental biogenic amine transporters: in vivo function, regulation and pathobiological significance. Placenta 1999;20:3-11.

20. Bzoskie L, Blount L, Kashiwai K, Tseng YT, Hay WW Jr, Padbury JF. Placental norepinephrine clearance: in vivo measurement and physiological role. Am J Physiol 1995;269:E145-9. [CrossRef]

21. Slotkin TA, Seidler FJ. Adrenomedullary catecholamine release in the fetus and newborn: secretory mechanisms and their role in stress and survival. J Dev Physiol 1988;10:1-16.

22. Affinati $A H, A u c h u s ~ R J$. Endocrine causes of hypertension in pregnancy. Gland Surg 2020;9:69-79. [CrossRef]

23. Kamoun M, Mnif MF, Charfi N, Kacem FH, Naceur BB, Mnif F, et al. Adrenal diseases during pregnancy: pathophysiology, diagnosis and management strategies. Am J Med Sci 2014;347:64-73.

24. Lal G, Clark OH. Thyroid, parathyroid and adrenal. In: Brunicardi FC, Andersen DK, Billiar TR, Dunn DL, Kao LS, Hunter JG, et al, editors. Schwartz's Principles of Surgery. 11th ed. Newyork: McGraw Hill; 2019. p. 1625-704.

25. Lenders JW, Willemsen JJ, Eisenhofer G, Ross HA, Pacak K, Timmers $\mathrm{HJ}$, et al. Is supine rest necessary before blood sampling for plasma metanephrines? Clin Chem 2007;53:352-4. [CrossRef]

26. Cisco RM, Grondal S, Hamberger B. Adrenal physiology. In: Clark $\mathrm{OH}$, Duh QY, Kebebew E, Gosnell JE, Shen WT, editors. Textbook of Endocrine Surgery. 3rd ed. Jaypee Brothers Medical Publishers; 2016. p. 973-78. [CrossRef]
27. Eisenhofer G, Prejbisz A, Peitzsch M, Pamporaki C, Masjkur J, Rogowski-Lehmann N, et al. Biochemical Diagnosis of Chromaffin Cell Tumors in Patients at High and Low Risk of Disease: Plasma versus Urinary Free or Deconjugated O-Methylated Catecholamine Metabolites. Clin Chem 2018;64:1646-56. [CrossRef]

28. Nölting S, Ullrich M, Pietzsch J, Ziegler CG, Eisenhofer G, Grossman A, et al. Current Management of Pheochromocytoma/Paraganglioma: A Guide for the Practicing Clinician in the Era of Precision Medicine. Cancers (Basel) 2019;11:1505. [CrossRef]

29. Bílek R, Vlček P, Šafařík L, Michalský D, Novák K, Dušková J, et al. Chromogranin A in the Laboratory Diagnosis of Pheochromocytoma and Paraganglioma. Cancers (Basel) 2019;11:586. [CrossRef]

30. McHenry CM, Hunter SJ, McCormick MT, Russell CF, Smye MG, Atkinson $\mathrm{AB}$. Evaluation of the clonidine suppression test in the diagnosis of phaeochromocytoma. J Hum Hypertens 2011;25:4516. [CrossRef]

31. Plouin PF, Amar L, Dekkers OM, Fassnacht M, Gimenez-Roqueplo AP, Lenders JW, et al; Guideline Working Group. European Society of Endocrinology Clinical Practice Guideline for long-term followup of patients operated on for a phaeochromocytoma or a paraganglioma. Eur J Endocrinol 2016;174:G1-10. [CrossRef]

32. Hampel H, Bennett RL, Buchanan A, Pearlman R, Wiesner GL; Guideline Development Group, American College of Medical Genetics and Genomics Professional Practice and Guidelines Committee and National Society of Genetic Counselors Practice Guidelines Committee. A practice guideline from the American College of Medical Genetics and Genomics and the National Society of Genetic Counselors: referral indications for cancer predisposition assessment. Genet Med 2015;17:70-87. [CrossRef]

33. Nockel P, El Lakis M, Gaitanidis A, Yang L, Merkel R, Patel D, et al. Preoperative genetic testing in pheochromocytomas and paragangliomas influences the surgical approach and the extent of adrenal surgery. Surgery 2018;163:191-6. [CrossRef]

34. Čtvrtlík F, Koranda P, Schovánek J, Škarda J, Hartmann I, Tüdös Z. Current diagnostic imaging of pheochromocytomas and implications for therapeutic strategy. Exp Ther Med 2018;15:3151-60.

35. Woo S, Suh CH, Kim SY, Cho JY, Kim SH. Pheochromocytoma as a frequent false-positive in adrenal washout $\mathrm{CT}$ : A systematic review and meta-analysis. Eur Radiol 2018;28:1027-36. [CrossRef]

36. Wiseman D, Lakis ME, Nilubol N. Precision Surgery for Pheochromocytomas and Paragangliomas. Horm Metab Res 2019;51:47082. [CrossRef]

37. Itani M, Mhlanga J. Imaging of Pheochromocytoma and Paraganglioma. In: Mariani-Costantini R, editor. Paraganglioma: A Multidisciplinary Approach. Brisbane (AU): Codon Publications; 2019 Jul 2. Chapter 3. [CrossRef]

38. Taïeb D, Hicks RJ, Hindié E, Guillet BA, Avram A, Ghedini P, et al. European Association of Nuclear Medicine Practice Guideline/Society of Nuclear Medicine and Molecular Imaging Procedure Standard 2019 for radionuclide imaging of phaeochromocytoma and paraganglioma. Eur J Nucl Med Mol Imaging 2019;46:2112-37. [CrossRef] 
39. Friedman NC, Hassan A, Grady E, Matsuoka DT, Jacobson AF. Efficacy of thyroid blockade on thyroid radioiodine uptake in 1231mIBG imaging. J Nucl Med 2014;55:211-5. [CrossRef]

40. Han S, Suh CH, Woo S, Kim YJ, Lee JJ. Performance of 68Ga-DOTAConjugated Somatostatin Receptor-Targeting Peptide PET in Detection of Pheochromocytoma and Paraganglioma: A Systematic Review and Metaanalysis. J Nucl Med 2019;60:369-76. [CrossRef]

41. Kan Y, Zhang S, Wang W, Liu J, Yang J, Wang Z. 68Ga-somatostatin receptor analogs and 18F-FDG PET/CT in the localization of metastatic pheochromocytomas and paragangliomas with germline mutations: a meta-analysis. Acta Radiol 2018;59:1466-74.

42. Taïeb D, Jha A, Guerin C, Pang Y, Adams KT, Chen CC, et al. 18FFDOPA PET/CT Imaging of MAX-Related Pheochromocytoma. J Clin Endocrinol Metab 2018;103:1574-82. [CrossRef]

43. Antonio K, Valdez MMN, Mercado-Asis L, Taïeb D, Pacak K. Pheochromocytoma/paraganglioma: recent updates in genetics, biochemistry, immunohistochemistry, metabolomics, imaging and therapeutic options. Gland Surg 2020;9:105-23. [CrossRef]

44. Neumann HPH, Young WF Jr, Eng C. Pheochromocytoma and Paraganglioma. N Engl J Med 2019;381:552-65. [CrossRef] 